\title{
Research
}

\section{Fire characteristics and environmental conditions shape plant communities via regeneration strategy}

\author{
Nicola J. Day*, Alison L. White*, Jill F. Johnstone, Geneviève É. Degré-Timmons, Steven G. Cumming, \\ Michelle C. Mack, Merritt R. Turetsky, Xanthe J. Walker and Jennifer L. Baltzer
}

N. J. Day* (https://orcid.org/0000-0002-3135-7585) ■ (njday.ac@gmail.com), A. L. White*, G. É. Degré-Timmons and J. L. Baltzer (https://orcid. org/0000-0001-7476-5928), Biology Dept, Wilfrid Laurier Univ., Waterloo, ON, Canada. NJD also at: School of Science, Auckland Univ. of Technology, Auckland, New Zealand. Present address of ALW: Ministry of Natural Resources and Forestry, Peterborough, ON, Canada. - J. F. Johnstone, Dept of Biology, Univ. of Saskatchewan, Saskatoon, SK, Canada, and Inst. of Arctic Biology, Univ. of Alaska Fairbanks, Fairbanks, AL, USA. - S. G. Cumming and GEDDT, Dept of Wood and Forest Sciences, Laval Univ., Quebec City, QC, Canada. - M. C. Mack and X. J. Walker (https://orcid.org/0000-0002-2448-691X), Center for Ecosystem Science and Society, Northern Arizona Univ., Flagstaff, AZ, USA. - M. R. Turetsky, Inst. of Arctic and Alpine Research, Univ. of Colorado Boulder, CO, USA.

\section{Ecography}

43: 1464-1474, 2020

doi: $10.1111 /$ ecog.05211

Subject Editor: Flávia Costa Editor-in-Chief: Miguel Araújo

Accepted 1 July 2020

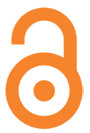

Climate change is altering disturbance regimes outside historical norms, which can impact biodiversity by selecting for plants with particular traits. The relative impact of disturbance characteristics on plant traits and community structure may be mediated by environmental gradients. We aimed to understand how wildfire impacted understory plant communities and plant regeneration strategies along gradients of environmental conditions and wildfire characteristics in boreal forests. We established 207 plots $\left(60 \mathrm{~m}^{2}\right)$ in recently burned stands and 133 plots in mature stands with no recent fire history in comparable gradients of stand type, site moisture (drainage) and soil organic layer (SOL) depth in two ecozones in Canada's Northwest Territories. At each plot, we recorded all vascular plant taxa in the understory and measured the regeneration strategy (seeder, resprouter, survivor) in burned plots, along with seedbed conditions (mineral soil and bryophyte cover). Dispersal, longevity and growth form traits were determined for each taxon. Fire characteristics measured included proportion of pre-fire SOL combusted (fire severity), date of burn (fire seasonality) and pre-fire stand age (time following fire). Results showed understory community composition was altered by fire. However, burned and mature stands had similar plant communities in wet sites with deep SOL. In the burned plots, regeneration strategies were determined by fire severity, drainage and pre- and post-fire SOL depth. Resprouters were more common in wet sites with deeper SOL and lower fire severity, while seeders were associated with drier sites with thinner SOL and greater fire severity. This led to drier burned stands being compositionally different from their mature counterparts and seedbed conditions were important. Our study highlights the importance of environment-wildfire interactions in shaping plant regeneration strategies and patterns of understory plant community structure across landscapes, and the overriding importance of SOL depth and site drainage in mediating fire severity, plant regeneration and community structure.

Keywords: plant functional traits, RLQ and fourth corner analysis, soil drainage, taiga plains, taiga shield, vegetation change

(C) 2020 The Authors. Ecography published by John Wiley \& Sons Ltd on behalf of Nordic Society Oikos *Shared first authorship.

This is an open access article under the terms of the Creative Commons Attribution License, which permits use, distribution and reproduction in any medium, provided the original work is properly cited. 


\section{Introduction}

Disturbance regimes are changing in many regions globally, generating concerns about impacts on plant biodiversity and ecosystem function (Brose and Hillebrand 2016, Seidl et al. 2016). Disturbances and extreme environmental events are key drivers of plant community structure because they act as filters for individuals with particular traits and regeneration strategies (Grime 1977, Bellingham and Sparrow 2000, Pausas and Keeley 2014, Johnstone et al. 2016). A common regeneration strategy in fire-dominated systems is resprouting, and basal resprouting is common in systems that have evolved with severe fires (Bellingham and Sparrow 2000, Bond and Midgley 2001). However, resprouting ability in an individual can decline when fires are severe enough to kill meristems or frequent enough to prevent plants from rebuilding root material between fire events (Bellingham and Sparrow 2000, Clarke et al. 2013). Moreover, environmental conditions such as poor site drainage and thick organic soils may protect meristems from burning to support resprouting, or support species that are able to resprout (Hollingsworth et al. 2013). We expect fire and environmental filtering impacts on plant individuals to extend to community-level patterns in composition or richness. Thus, understanding plant regeneration strategies along gradients of environmental and fire conditions is a key component of anticipating where shifts in plant community structure may occur in response to changes in disturbance.

Boreal forests cover 1.9 Bha globally and fire is the dominant disturbance in this biome (Gauthier et al. 2015). Plants in the boreal forest exhibit a suite of traits that have historically enabled them to self-replace after fire, including resprouting and aerial seedbanks (Johnstone et al. 2010a, Hollingsworth et al. 2013). Boreal forest fires generally kill all trees and the majority of combustion occurs in the soil organic layer (SOL) (Boby et al. 2010, Walker et al. 2018a), characteristics which favour basal resprouting (Bellingham and Sparrow 2000, Clarke et al. 2013). For vascular plants in the boreal region, the majority of individuals in post-fire stands regenerate by resprouting: from $40 \%$ in black spruce Picea mariana-dominated stands in Alaska (Hollingsworth et al. 2013) to $70 \%$ in mixed stands of balsam fir Abies balsamea, black spruce and paper birch Betula papyrifera in Quebec (De Grandpré et al. 1993). Other understory plants develop soil seedbanks to survive fires, such as Luzula pilosa in Sweden (Schimmel and Granström 1996, Ryan 2002). These various regeneration strategies comprise ecological legacies that promote self-replacement following fire, meaning recovery to pre-fire composition and structure, i.e. ecological resilience (Clarke et al. 2013, Hollingsworth et al. 2013, Johnstone et al. 2016).

High latitude forests are experiencing rapid warming and associated intensification of wildfire activity due to climate change (Brandt et al. 2013, Gauthier et al. 2015), particularly in western North America (de Groot et al. 2013, Romero-Lankao et al. 2014, Wotton et al. 2017, Coops et al. 2018), which may lead to a mismatch between the disturbance regime and mechanisms that currently favour resilience of plant communities (Seidl et al. 2016). Severe burning, for example, has been shown to drive state changes in canopy dominance in boreal forests (Greene et al. 2007, Johnstone et al. 2010b). However, most plant biodiversity and wildlife resources are in the understory, where the implications of changing fire activity are less clear (Hart and Chen 2006, Johnstone et al. 2010a, Hollingsworth et al. 2013). Since initial post-fire plant composition is representative of that of subsequent decades (Johnstone et al. 2004, Day et al. 2017), changes in species composition caused by fire may have long-term consequences for biodiversity.

The role of fire and environmental conditions in determining regeneration characteristics and subsequent plant communities is challenging to understand from studies in a single stand type with similar environmental conditions (e.g. black spruce stands). Fire severity appears to be the key driver of plant community composition and richness after fire in Alaska, with site drainage and depth of residual SOL as secondary predictors (Bernhardt et al. 2011, Hollingsworth et al. 2013). In other cases, pre-fire stand type and associated environmental conditions are primary determinants of plant communities, not fire characteristics per se (Purdon et al. 2004, Day et al. 2017, Whitman et al. 2018). Certain environmental conditions may better support resprouting over seeding strategies. For example, poorly-drained areas with deep organic soils provide excellent environmental conditions for slow growing, stress-tolerant species capable of regeneration from both above and belowground tissue (Grime 1977, Schimmel and Granström 1996) and these same conditions also protect sites from complete burning of the SOL (Johnstone and Chapin 2006, Walker et al. 2018a). Conversely, well-drained areas with shallower organic soils are more likely to experience complete SOL combustion and expose mineral soil, which promotes regeneration from seed and can reduce plant species richness (Hollingsworth et al. 2013, Pinno and Errington 2016) and reduce soil microbes that facilitate plant growth (Day et al. 2019). This suggests that plant communities in some parts of the landscape may be more likely to undergo shifts in composition with an intensifying fire regime.

Here, we aim to understand understory plant community structure and post-fire regeneration strategies along gradients of environmental conditions and wildfire characteristics. In 2014, 2.85 Mha of boreal forest burned in the Taiga Plains and Taiga Shield ecozones of the Northwest Territories, Canada (Walker et al. 2018a), the largest annual area burned in the region since records began in 1965 (Canadian Interagency Forest Fire Centre 2014). We assessed understory vascular plant community structure across ecozones along local gradients of site drainage in dominant stand types in the region in recently burned and mature stands. The sampling of 340 plots was designed to address three main research questions.

1) Does fire alter understory plant composition and in what parts of the landscape does this occur? Our hypothesis was that stands with poor drainage with deep SOL recovering from recent fires would be compositionally similar to mature 
stands regardless of fire severity. In contrast, we expected that after fire, well-drained stands with shallow SOL would be compositionally distinct from mature stands due to greater proportional combustion of SOL and associated changes in the regeneration environment.

2) What are the underlying relationships between plant traits relating to regeneration, and environmental and fire characteristics that determine post-fire plant community assembly and composition? Our hypothesis was that basal resprouting would be common. However, we predicted that as fire severity increased a greater proportion of the plant community would regenerate from seed due to mortality of meristems and loss of resprouting potential (Schimmel and Granström 1996, Bellingham and Sparrow 2000, Hollingsworth et al. 2013).

3) What are the main drivers of understory plant taxa richness following fire, in terms of environmental and wildfire characteristics? We hypothesised that areas with very severe or frequent fires would have lower species richness due to meristem mortality (Hollingsworth et al. 2013, Whitman et al. 2018). However, stand type and variables related to site drainage would also be important, with well-drained areas and pine-dominated stands having greater richness (Day et al. 2017, Whitman et al. 2018).

\section{Methods}

\section{Study area}

This study spanned the Taiga Plains (hereafter Plains) and Taiga Shield (hereafter Shield) ecozones in the Northwest Territories (NWT), Canada. The Plains is a mix of undulating glacial till and peatlands with permafrost in wetter areas (Zhang et al. 1999, Ecosystem Classification Group 2009). It is characterised by open, slow growing forest dominated by black spruce Picea mariana and/or jack pine Pinus banksiana. The Shield, in the eastern part of the NWT, has hilly preCambrian bedrock with thin till, overlain in places by layers of clay, sand and gravel (Ecosystem Classification Group 2008). Mean annual temperatures (1981-2010) in Hay River on the Plains $\left(60.82^{\circ} \mathrm{N},-115.79^{\circ} \mathrm{W}\right)$ and Yellowknife on the Shield $\left(62.45^{\circ} \mathrm{N},-114.37^{\circ} \mathrm{W}\right)$ are $-2.5^{\circ} \mathrm{C}$ and $-4.3^{\circ} \mathrm{C}$, respectively. Mean annual precipitation (1981-2010) in Hay River and Yellowknife is $336 \mathrm{~mm}$ and $228 \mathrm{~mm}$, respectively (Environment and Climate Change Canada 2017).

\section{Site selection}

Between June and August 2015, 207 permanently-marked plots were established across seven 2014 burn scars; 121 plots on the Plains and 86 plots on the Shield (Supplementary material Appendix 1 Fig. A1). Plot locations were chosen using a stratified random sampling design in pre-fire coniferdominated stands (Walker et al. 2018a, b). Random points were generated within these strata and constrained to within $1 \mathrm{~km}$ of roads or shorelines for accessibility. In 2016-2018, plots were established in areas with no recorded burn history since records began in 1965 , with 70 plots on the Plains and 63 plots on the Shield. These mature stands were selected to be geographically close to sampled 2014 fire scars (Supplementary material Appendix 1 Fig. A1). We used the Land Cover Class of Canada to ensure mature plots were the same vegetation types as the burned plots based on their prefire classification (Latifovic et al. 2008). On the ground, the randomly-generated point was assigned a soil moisture category according to drainage, where xeric was the driest and subhygric was the wettest (Johnstone et al. 2008). Within $500 \mathrm{~m}$ of the initial plot we found at least one, but usually two plots of a different moisture class, capturing a range of drainage conditions. This group of plots is termed a site.

\section{Field measurements}

Each plot comprised two parallel $30 \mathrm{~m}$ transects spaced $2 \mathrm{~m}$ apart $\left(60 \mathrm{~m}^{2}\right.$ belt $)$, running due north. To assess the understory plant community, five $1 \times 1 \mathrm{~m}$ quadrats were established at $6 \mathrm{~m}$ intervals along the eastern transect. Presence of each vascular plant taxon was recorded in each quadrat, for all plants shorter than $1.3 \mathrm{~m}$. We calculated plant abundance for each plot by summing the number of quadrats in which each taxon occurred. Most plants were identified to species, but due to the small stature and reproductive immaturity of post-fire recruits some plants were only identified to genus or, seldom, to family. Plant identifications were verified using Porsild and Cody (1980), Johnson et al. (1995), and the National Herbarium of Canada. Representative specimens were deposited in the Wilfrid Laurier University Herbarium (code WLU). Nomenclature follows the database of vascular plants of Canada (Brouillet et al. 2010).

In burned plots, we estimated percent cover within each quadrat of seedbed conditions: exposed mineral soil and early colonizing bryophytes (Ceratodon spp. and Marchantia spp.). We calculated the mean percent cover of each of these variables across quadrats within a plot. A subset of 98 plots on the Plains were resurveyed for vegetation in spring and summer of 2016 ( $2 \mathrm{yr}$ post-fire); there were no significant differences in plant composition (Mantel test; data not shown) so we present only the 2015 data.

We identified and counted every tree of all sizes, including saplings, in the $60 \mathrm{~m}^{2}$ plot to assess stand canopy composition. In burned stands these measures included standing and fallen trees killed by fire to obtain a measure of pre-fire stand type. Black spruce was the dominant tree species in these forests and as such, stand type was characterised as the proportion of black spruce stems within the plot; this explanatory variable represents a gradient of black spruce to jack pine.

The rapid germination of tree seedlings in the initial years following fire (Greene and Johnson 1999) means that the age of the stand is a good estimate of time following fire. To estimate stand age, we collected basal tree discs or cores just above the root collar of five trees of each dominant conifer representing the dominant size class in each plot, including dead trees in the burned stands. Samples were sanded 
with progressively finer grits then scanned and rings were counted in Cybis CooRecorder v.7.8 (Larsson 2006) or WinDendro 2009 (Regent Instruments Canada 2009). In most cases, tree ages within plots were clearly structured by recruitment cohorts and clustered within $20 \mathrm{yr}$ of each other (see Walker et al. 2018a for details). Stand age was similar in burned and mature stands (Supplementary material Appendix 1 Table A1).

Our metric of fire severity in the burned plots was the proportion of SOL combusted, which was calculated as burn depth/pre-fire SOL (Boby et al. 2010, Walker et al. 2018b). Burn depth, pre-fire SOL thickness and proportion SOL combusted were estimated using measurements in the 2014 burned plots combined with calibrations from mature plots; details and data are provided in Walker et al. (2018b, c). Briefly, we measured SOL depth at 10-20 points in mature and burned plots. In plots with black spruce, burn depth was estimated as the height of adventitious roots above the residual SOL on ten trees per plot plus an offset $(-3 \mathrm{~cm})$ based on the depth of adventitious roots below the green moss surface measured in mature stands (Walker et al. 2018b). In plots where only jack pine was present, burn depth was based on moisture class-specific estimates of residual SOL compared to SOL depth in mature plots. For all stand types, pre-fire SOL was calculated by summing residual SOL and burn depth.

\section{Vascular plant trait measurements}

At each burned plot, regeneration strategies of individual vascular plants were determined by excavating individuals at least $1 \mathrm{~m}$ away from quadrats. We aimed to record regeneration strategy of two individuals of each taxon present at each plot. Within each ecozone, regeneration strategy for each taxon was calculated as the proportion of individuals across all burned plots that were regenerating from seed (seeders), resprouting from belowground meristems (resprouters) and survived intact (survivor). We further determined growth form (shrub, forb, tree, graminoid or seedless vascular plant), mechanism of seed dispersal (wind or animal) and plant longevity (annual, biennial or perennial) for all vascular plant species encountered using a combination of field observations and literature searches (Johnson et al. 1995, Brouillet et al. 2010, USDA 2017). Where we could not identify taxa to species level, we used the most common category of the trait for the taxonomic level that could be resolved.

\section{Data analyses}

Analyses were performed using R v.3.6.3 (R Core Development Team) and packages tidyverse (Wickham 2017), vegan (Oksanen et al. 2019), egg (Auguie 2018) and ade4 (Dray and Dufour 2007). $\mathrm{R}$ code is provided (Supplementary material Appendix 1). We removed rare taxa from analyses, defined as those found in only one quadrat and one plot in each ecozone (Burned: Plains: 81/112 taxa retained; Shield: 38/46 retained; Mature: Plains: 95/117 retained; Shield: 49/58 retained).
Drivers of plant composition in mature and burned stands

To investigate drivers of composition in mature and burned stands, we undertook distance-based redundancy analyses for each ecozone (db-RDA; Legendre and Anderson 1999), specifying Bray-Curtis dissimilarity. Predictors included fire variables (burned or mature, stand age) and environmental variables (SOL depth, stand type). Pre-fire values were used for burned plots and all continuous variables were centered and standardized. Variables were not highly correlated $(r<0.6)$. SOL depth can be considered a surrogate for drainage due to their high correlation (Supplementary material Appendix 1 Fig. A2). We used variance partitioning to assess the relative contributions of environmental and fire variables to plant taxa composition (Borcard et al. 2011).

\section{Roles of plant traits, environment and fire characteristics in determining plant composition post-fire}

To understand how environmental and fire variables and plant traits influence community assembly and composition in the burned plots only, we used complementary multivariate approaches: RLQ and the fourth-corner methods. The RLQ summarises the joint multivariate structure of three matrices: environmental variables ( $\mathrm{R}$ matrix), community composition (L matrix) and taxon-level functional traits (Q' matrix; Dray and Legendre 2008). RLQ maximises the squared covariances between orthogonal linear combinations of environmental covariates and traits, as mediated by taxon abundances at each plot.

The fourth-corner analysis takes the weighted row scores from the RLQ matrices and tests for bivariate associations between each environmental variable and trait, with permutation tests of significance. p-values were calculated using the default permutation model (model 6), linking matrices $\mathrm{L}$ and $\mathrm{Q}^{\prime}$ and correcting for type I error rates (Dray et al. 2014). We conducted 49999 permutations of sites and taxa testing the null hypothesis that the distribution of taxa with fixed (i.e. plot-independent) traits is not influenced by environmental conditions (model 4). p-values were corrected for multiple tests by the false discovery rate method (Benjamini and Hochberg 1995).

The RLQ and fourth corner analyses allow collinearity among variables so we used the following environmental and fire variables: pre-fire SOL depth, post-fire SOL depth, fire severity, date of burn, pre-fire stand type (proportion black spruce), pre-fire stand age, mineral soil cover, bryophyte cover and moisture class (drainage). The taxon-level plant trait variables included: the proportion of individuals using each regeneration strategy across the dataset (seeder, resprouter from meristem or survivor), growth form, seed dispersal mechanism and longevity. Nominal-scale categorical variables were coded as dummy variables resulting in 11 environmental variables and 10 plant traits. Since we did not collect regeneration strategy information for all taxa due to rarity of some plants, the analysis included 68 and 36 taxa on the Plains and Shield, respectively. 

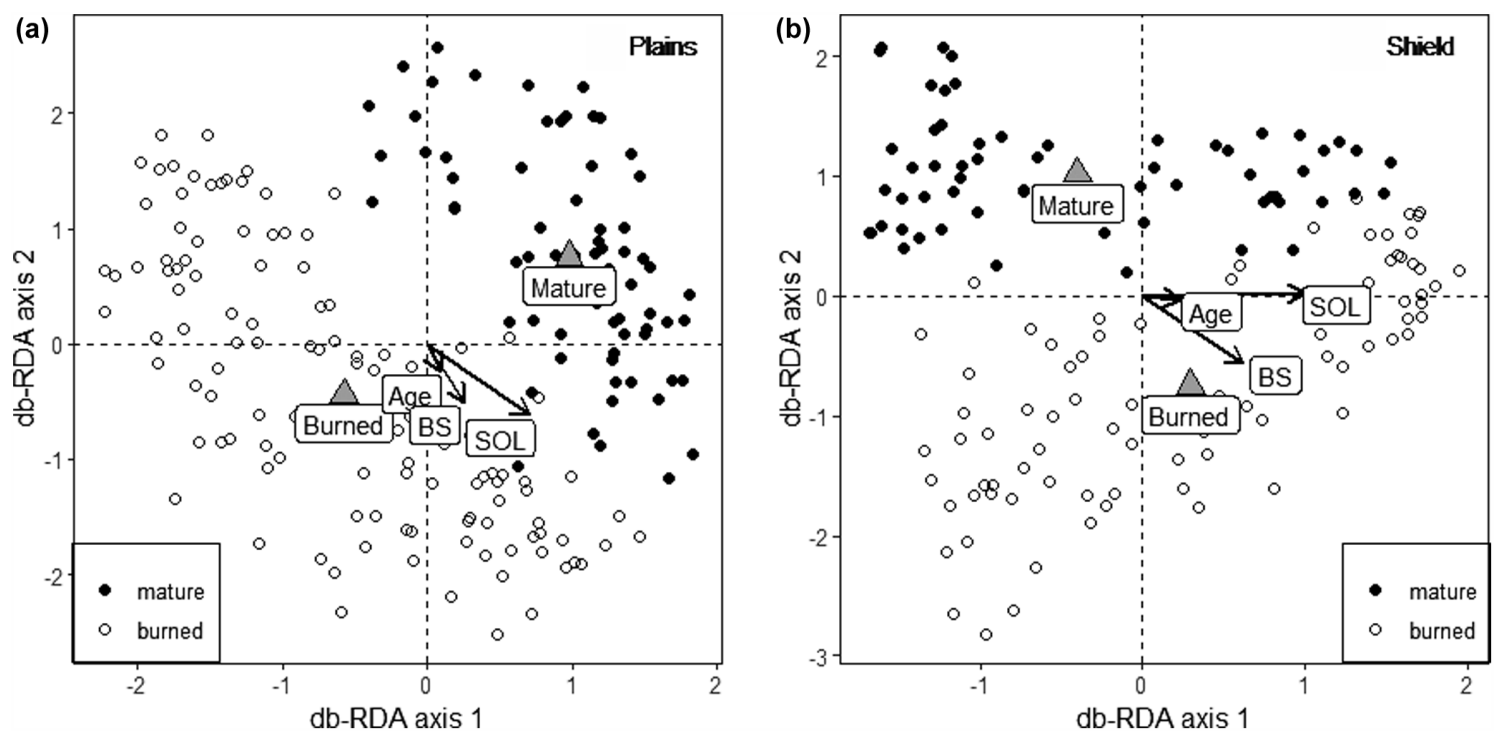

Figure 1. Results from distance based redundancy analyses (db-RDA) with environmental and fire drivers of species composition in mature and burned plots in on the (a) Plains and (b) Shield in boreal forests in the Northwest Territories, Canada. Vectors are shown as arrows for continuous predictors and centroids are shown as triangles for the factor variable (mature or burned).

\section{Assessing drivers of vascular plant taxa richness post-fire}

We modelled plot-level vascular plant taxa richness as a Poisson response (count data) in a generalised linear model with the following predictor variables: burn scar, fire severity, date of burn, pre-fire stand type (proportion black spruce), pre-fire stand age and percent cover of mineral soil. These variables best represented our hypotheses and were not highly correlated $(r<0.6)$.

\section{Results}

\section{Drivers of plant composition in mature and burned stands}

Taxon accumulation curves approached sampling saturation in both ecozones in burned and mature stands (Supplementary material Appendix 1 Fig. A3). Results from dbRDAs showed similar importance of drivers of plant composition across ecozones. Burned plots differed from mature plots (Fig. 1). The vector lengths show SOL depth was an important differentiator of composition, which correlated with drainage (Supplementary material Appendix 1 Fig. A2). Burned plots with deep pre-fire SOL (wetter) had more similar species composition to mature plots than burned plots with shallow pre-fire SOL (drier). Composition also differed by stand type. Stand age was the least important driver of composition in both ecozones. Similar patterns are shown using unconstrained ordinations (principal co-ordinates analyses; Supplementary material Appendix 1 Fig. A4).

Variance partitioning showed that fire variables were less important for plant composition on the Shield than on the Plains, relative to environmental variables (Table 1). On the Plains, environmental and fire variables explained the same amount of variation in composition. On the Shield, environmental variables alone accounted for the vast majority of explained variation. Unexplained variation was high in all analyses. These results were further supported by permutational analysis of variance; on the Plains, the effect of fire explained most of the variation in composition, followed by SOL depth and stand type, while on the Shield SOL depth and stand type were more important than fire (Supplementary material Appendix 1 Table A2).

\section{Roles of plant traits, environment and fire characteristics in determining plant composition post-fire}

We assessed regeneration strategy of 3918 individuals: 2561 $(65.2 \%)$ were resprouters, 1105 (28.1\%) were seeders and $252(6.4 \%)$ survived intact. Results from the RLQ and fourthcorner analyses showed there were similar trait-environment

Table 1. Results from variance partitioning with environmental and fire drivers of species composition in mature and burned plots in on the Plains and Shield in boreal forests in the Northwest Territories, Canada.

\begin{tabular}{llccrc}
\hline Ecozone & Variables & $\mathrm{R}^{2}(\mathrm{adj})$ & $\mathrm{df}$ & $\mathrm{F}$ & $\mathrm{p}$ \\
\hline Plains & All & 0.17 & 4 & 10.85 & 0.001 \\
& Environment alone & 0.08 & 2 & 9.86 & 0.001 \\
& Environment + fire & 0.09 & 2 & 10.81 & 0.001 \\
& Fire alone & 0.08 & 2 & 10.51 & 0.001 \\
& Fire + environment & 0.09 & 2 & 10.15 & 0.001 \\
Shield & All & 0.25 & 4 & 13.12 & 0.001 \\
& Environment alone & 0.19 & 2 & 19.08 & 0.001 \\
& Environment+fire & 0.23 & 2 & 22.74 & 0.001 \\
& Fire alone & 0.02 & 2 & 2.90 & 0.002 \\
& Fire+environment & 0.06 & 2 & 5.72 & 0.001 \\
\hline
\end{tabular}




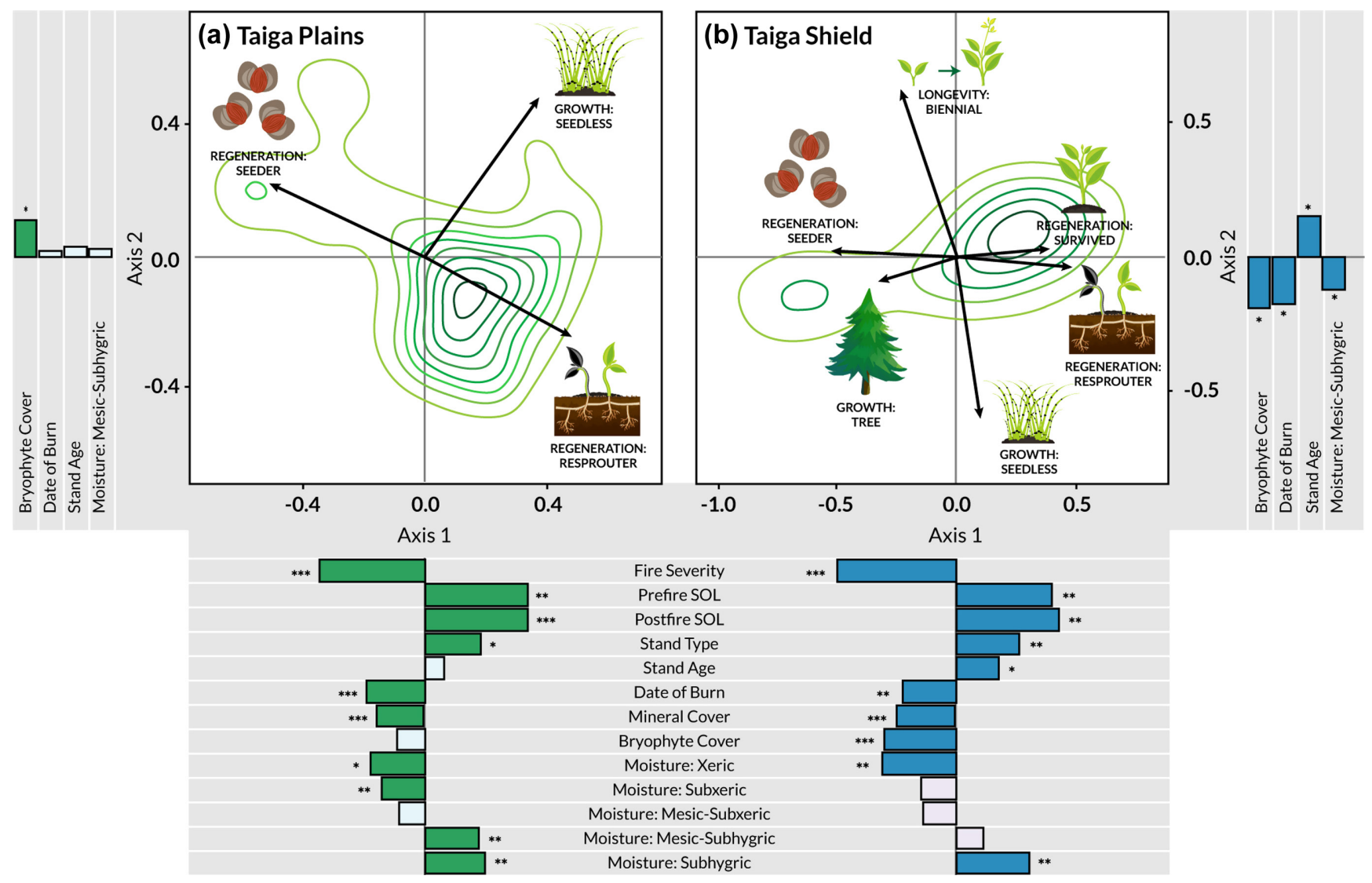

Figure 2. Results of RLQ analyses for the (a) Plains $(n=121)$ and (b) Shield $(n=86)$ in burned plots in boreal forests of the Northwest Territories, Canada. Contour lines show the density of species, with density increasing from light to dark green (note: species scores were scaled by a factor of 0.2$)$. Vectors for the significant trait variables based on fourth-corner analyses $(p<0.05)$ are shown on the graph. Bars represent correlation values $(r)$ for the fire and environmental variables for each axis. Moisture is site drainage. Significant correlations based on fourth-corner analyses where ${ }^{*} \mathrm{p}<0.05,{ }^{* *} \mathrm{p}<0.01$ and ${ }^{* * *} \mathrm{p}<0.001$. Note that only four variables are shown on axis 2 to ease viewing. Detailed results can be seen in Table 2, Supplementary material Appendix 1 Fig. A5, A6, Table A3, A4.

relationships that could explain species composition across both ecozones (Fig. 2). The first two RLQ axes captured most of the trait-environment cross-covariance on both the Plains (axis 1: 94.0\%; axis 2: 3.3\%) and the Shield (axis 1: 93.1\%; axis 2: $3.9 \%$; Table 2 ). Correlations between traits and environment/fire variables mediated by taxa were 0.34 for axis 1 and 0.14 for axis 2 on the Plains and 0.48 for axis 1 and 0.27 for axis 2 on the Shield (Table 2).

The fourth-corner analysis allowed us to test the statistical significance of the pairwise relationships between species compositional gradients (axes) and environmental/fire variables and traits derived from the RLQ. For axis 1 in both ecozones, we found a significant negative relationship with xeric moisture (dry), fire severity, mineral cover and date of burn, and a significant positive relationship with subhygric moisture (wet), pre-fire SOL depth, post-fire SOL depth and increasing black spruce proportion (Fig. 2; Supplementary material Appendix 1 Table A3, A4). This axis was significantly associated with regeneration strategy, with seeders negatively correlated and resprouters positively correlated. Resprouting was more associated with wet plots with lower fire severity and more black spruce; dominant taxa included Salix spp. and Rhododendron groenlandicum (Fig. 2, Supplementary material Appendix 1 Fig. A5, A6, Table A3, A4). Conversely, taxa were more likely to regenerate from seed in well-drained areas with lower fire severity, greater mineral soil cover and later date of burn; dominant taxa regenerating from seed included conifer seedlings and Capnoides sempervirens.

While the structure of the RLQ from the two ecozones was similar overall, there were some differences in significant variables and their relationships with each axis detected by the fourth-corner analysis. On the Shield, bryophyte cover was negatively correlated with axis 1 . Plants that survived intact were positively correlated with axis 1 (e.g. Vaccinium micropcarpum, Salix sp.). Plants that had the tree growth form were negatively correlated with axis 1 , such as paper birch and trembling aspen Populus tremuloides. Also on the Shield, pre-fire stand age was positively correlated with axes 1 and 2, but this was not significant on the Plains. On the Plains, axis 1 was negatively correlated with subxeric and positively correlated with mesic-subhygric and seedless plants (Equisetum spp.). On the Shield, axis 2 was negatively correlated with date 
Table 2. Summary of the RLQ analysis for burned plots on the Plains and Shield. The table shows eigenvalues and percentages of projected inertia accounted for by the first two RLQ axes. Covariance refers to the covariance between the two new sets of factorial scores projected onto the first two RLQ axes (square root of eigenvalue); correlation refers to correlations between traits and fire and environment mediated by taxa projected onto the first two RLQ axes; cumulative inertia refers to the variance of each set of factorial scores for environmental covariates and for traits computed in the RLQ analysis.

\begin{tabular}{lrrrrr}
\hline & \multicolumn{2}{c}{ Plains } & & \multicolumn{2}{c}{ Shield } \\
\cline { 2 - 3 } \cline { 5 - 6 } & Axis 1 & Axis 2 & & Axis 1 & Axis 2 \\
\hline Eigenvalues & 1.27 & 0.04 & & 3.47 & 0.15 \\
\% projected inertia & 94.04 & 3.32 & & 93.08 & 3.94 \\
Covariance & 1.13 & 0.21 & & 1.86 & 0.38 \\
Correlation & 0.34 & 0.14 & & 0.48 & 0.27 \\
Cumulative inertia & 4.27 & 5.66 & & 4.34 & 5.91 \\
$\quad$ (environment) & & & & & \\
Cumulative inertia (traits) & 2.54 & 4.23 & & 3.54 & 4.8 \\
\hline
\end{tabular}

of burn and mesic-subhygric, and seedless plants, while the biennial trait was positively correlated (Fig. 2, Supplementary material Appendix 1 Table A3). Bryophyte cover was positively correlated with axis 2 on the Plains and negatively correlated with axis 2 on the Shield.

\section{Assessing drivers of vascular plant taxa richness post-fire}

Burned plots on the Plains had greater vascular taxa richness (mean 12 taxa, range 1-22) than the Shield (mean 8, range 1-19); this is likely because the species pool was smaller on the Shield than the Plains (Supplementary material Appendix 1 Fig. A3). Fire severity was a significant driver of post-fire taxa richness in both ecozones, where greater combustion reduced richness (Table 3). Date of burn was a significant predictor of richness on the Plains, where plots that burned later in the season had lower richness than those burning earlier. There were also differences in taxa richness between burn scars on the Plains, where plots in burn scars ZF20 and ZF46 had greater richness than those in SS003 (Supplementary material Appendix 1 Fig. A1), the most southern burn scar comprised of mainly black spruce-dominated stands. On the Shield, richness was higher in stands with greater pre-fire proportion of black spruce (stand type; Table 3 ).

\section{Discussion}

We have shown the importance of environmental conditions in shaping the effect of wildfire on plant regeneration strategies and subsequent understory plant community structure in boreal forests. Across two ecozones in Canada's high latitude boreal forests, environmental and fire characteristics determined dominant regeneration strategies: resprouters were more common in poorly-drained sites with deeper soil organic layers (SOL) and lower fire severity, while seeders were associated with well-drained sites with thinner SOL and higher fire severity. This led to wet stands (poorly-drained) with thick SOL that burned being compositionally similar to mature stands of comparable drainage, while dry stands (welldrained) with high proportional SOL combustion differed from their mature counterparts. Thick SOL characteristic of wet landscape positions provides a critical pool of belowground meristems for resprouting (Schimmel and Granström 1996), while being a potential challenge for seed colonisation following fire due to dry surface conditions of burned organic soils (Johnstone et al. 2010a). Our results show the overriding importance of SOL depth and site drainage in mediating fire severity, plant regeneration and community structure.

In our study, $65 \%$ of all sampled plants in burned plots resprouted from belowground and this was strongly related to environmental and fire conditions, particularly site drainage

Table 3. Results from generalised linear models of post-fire taxa richness (Poisson response) in burned plots on the Plains and Shield one year after fire in boreal forests of the Northwest Territories, Canada. Significant predictors $(p<0.05)$ are presented in bold. All variables were centred and standardised. Fire severity was measured as the proportional combustion of the soil organic layer.

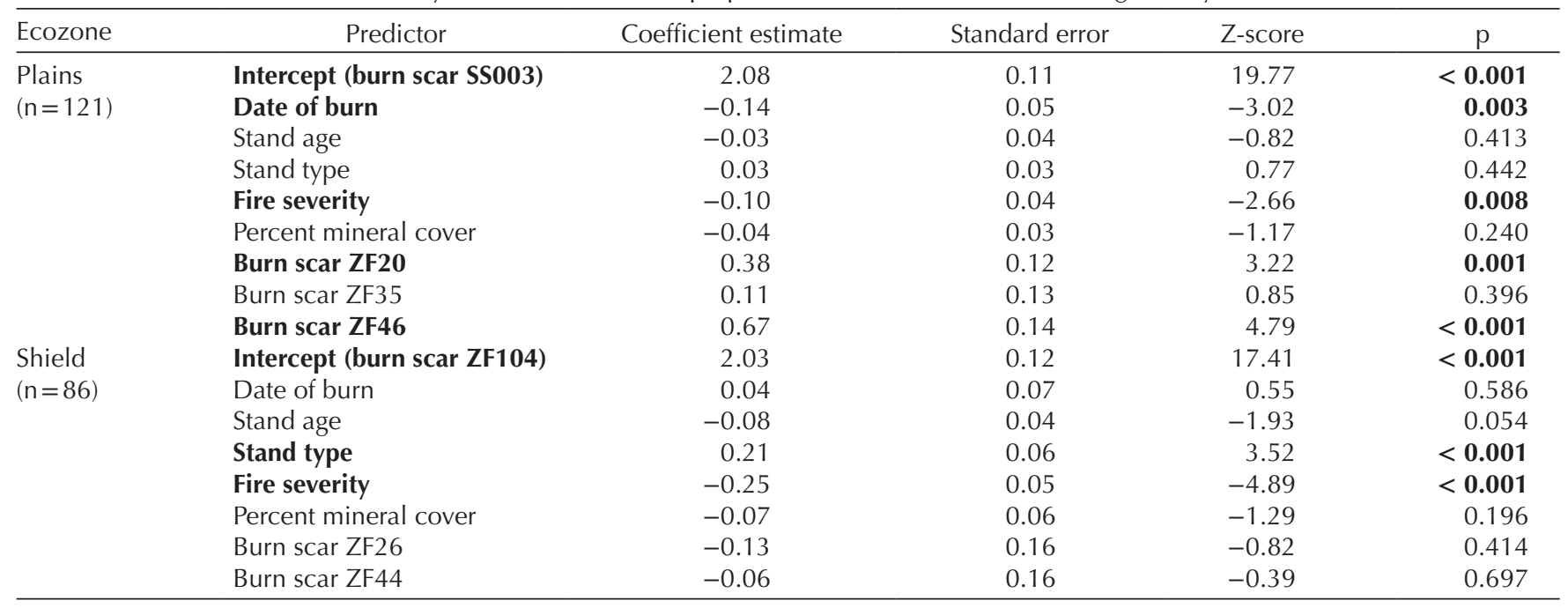




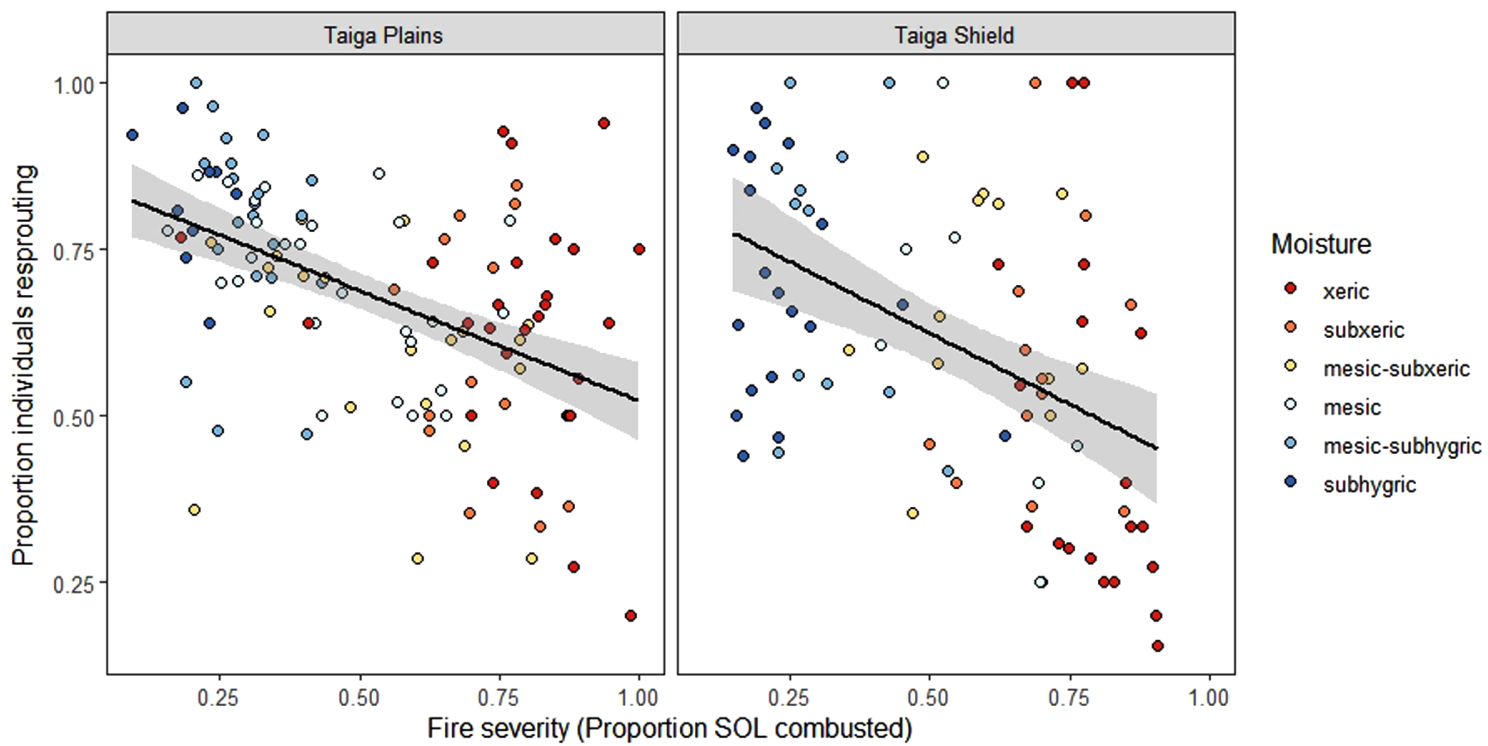

Figure 3. Relationship between fire severity (proportion soil organic layer combusted) and the proportion of individuals resprouting in burned plots on the (a) Plains $(n=121)$ and (b) Shield $(n=86)$ one year after fire. Each point represents a vegetation plot, colour-coded according to moisture class (site drainage). Results from the general linear models are in Supplementary material Appendix 1 Table A4.

(Fig. 2). Additional sampling in mature stands showed many taxa were rooted in organic horizons (Supplementary material Appendix 1 Methods and Results). During fire, wet sites had the lowest proportional combustion of pre-fire SOL (Walker et al. 2018a). Meristem mortality causing losses of resprouters may therefore explain declines in species richness with higher fire severity (greater proportional SOL combustion), as was observed after extreme wildfires in lodgepole pine forests (Turner et al. 1997). The lower proportion of resprouters in sites with higher fire severity was supported by post-hoc models (Fig. 3; Supplementary material Appendix 1 Table A5). However, mature plots with thin SOL also had lower richness than those with thicker SOL (Supplementary material Appendix 1 Fig. A7).

Dry plots with thin SOL that burned were dominated by seeders and had distinct plant composition compared to their mature forest counterparts (Fig. 1,2), indicating that these areas experienced the greatest shifts in composition due to fire. While we did not differentiate between seed regeneration from seedbanks compared to those dispersed from surrounding areas, at least some species were early successional species that form seedbanks in the mineral soil layer including Dracocephalum parviflorum, Geranium bicknellii and Capnoides sempervirens (Lyon and Stickney 1974, Schimmel and Granström 1996, Grandin and Rydin 1998). Soil seedbank species may persist in the mineral soil layer that does not combust, so may be tolerant of higher fire severity than resprouters rooted in the organic layer, thereby forming an ecological legacy in parts of the landscape that regularly experience complete SOL combustion. From these results, it may be expected that future warming and drying, leading to increased combustion, could reduce resprouter prevalence.
Seeders were more common in plots that burned later in the season (later date of burn) and with greater mineral soil cover, which is a superior seedbed (Fig. 2; Johnstone et al. 2010a, Hollingsworth et al. 2013). Many boreal vascular plants disperse their seeds early in the season (USDA 2017), suggesting that at least some of the plants may be from seeds dispersed from neighbouring areas in the spring following fire. It is possible that lower richness on the Plains with later date of burn is due to limited seed sources. Conversely, earlier season fires in poorly-drained sites may have given resprouting plants an opportunity to establish during the same year as the fire. The impact of date of burn is not attributable to greater combustion later in the season because there is no relationship between fire severity and date of burn at these plots (Walker et al. 2018a).

The association of resprouters with older stands on the Shield suggests that time is needed to build either regenerative structures or SOL accumulation to protect meristems, at least in some circumstances (Noble and Slatyer 1980, Enright et al. 2011, Clarke et al. 2013, Simpson et al. 2019). Declines in resprouters under short fire return intervals (younger stand ages) could be due to a combination of meristem damage and loss of older soil layers that have historically protected meristems (Walker et al. 2019). Future research questions to be investigated include: how long do plants need between fires to maintain their ability to resprout? How many times and under what conditions can plants resprout before they die? What is the relative importance of local aerial and soil seedbanks versus dispersal of seeds from off-site sources? Understanding these patterns in a landscape context would refine predictions of which plants and communities are most susceptible to changing disturbance conditions. 
Predicting the impacts of changing disturbance regimes on plant community assembly must account for how slow changing environmental factors, such as site drainage, affect the suite of potential plant community responses. We found strong similarities, but also important differences, in how plant communities responded to fire within different ecozones sharing the same regional species pool. Environmental variables were a key driver of plant composition, particularly on the Shield (Table 1). This could be because the Shield generally has only dry uplands or wet lowlands, while the Plains has more heterogeneous environmental characteristics. Drainage is a key determinant of nutrient cycling and plant communities in boreal forests (van Cleve et al. 1991, Bridge and Johnson 2000), including post-fire community assembly (Boiffin et al. 2015, Whitman et al. 2018). These studies highlight the need to characterise environmental differences in the response of ecosystems to extreme wildfire events, even within a region or biome.

Our study provides a predictive framework to forecast which parts of the boreal forest landscape are more likely to support resilient plant communities in the face of a changing fire regime. We show that wetter parts of the landscape experience lower fire severity and less dramatic compositional shifts in plant communities than dry areas, supporting the idea that wetter parts of the landscape may act as future climate change refugia (Stralberg et al. 2020). These landscape-level evaluations are crucial for the development of spatially-explicit ecological forecasting tools that can help inform management decisions regarding land-use, wildlife range planning and protected areas planning.

In conclusion, we have shown that plant regeneration strategies differ along environmental and fire severity gradients, driving post-fire community structure in two ecozones in boreal forests. Soil organic layer depth and site drainage conditions determined patterns of fire severity and thus were of overriding importance to vascular plant taxa regeneration strategies and subsequent composition and richness. Dry areas with shallow SOL and high fire severity were dominated by seeders and experienced the greatest compositional changes relative to mature stands in comparable environmental conditions. In contrast, resprouting was more common as fire severity declined and site drainage and pre-fire SOL increased; burned plots under these conditions had similar plant composition to their mature forest comparators. Our study highlights the importance of environment-fire interactions in shaping plant regeneration strategies and patterns of biodiversity.

\section{Data availability statement}

Part of the environmental and fire data is currently available here: X. J. Walker, B. M. Rogers, J. L. Baltzer, S. R. Cumming, N. J. Day, S. J. Goetz, J. F. Johnstone, M. R. Turetsky and M. C. Mack 2018. ABoVE: wildfire carbon emissions and burned plot characteristics, NWT, CA, 2014-2016. ORNL DAAC, Oak Ridge, TN, USA, <https://doi.org/10.3334/ ORNLDAAC/1561>, the remainder of the data are available from the Dryad Digital Repository: <https://doi. org/10.5061/dryad.76hdr7sth $>$ (Baltzer et al. 2020).

Acknowledgements - We thank A. Sniderhan for making the map and numerous students and technicians for field and lab assistance. Thanks to A. Trant, K. Standen and reviewers who provided helpful comments on earlier manuscript versions. B. Lee and Cryodragon, Inc. provided graphic art support for Fig. 2.

Funding - This article is part of Project 170 of the Government of the Northwest Territories (GNWT) Dept of Environment and Natural Resources Cumulative Impacts Monitoring Program (awarded to JLB, JFJ and SGC). Additional funding was provided by Natural Science and Engineering Research Council (NSERC: Changing Cold Regions Network), Northern Scientific Training Program, NSERC Discovery to MRT and JFJ, CFREF Global Water Futures funding for Northern Water Futures to JLB, a National Science Foundation DEB RAPID (grant \#1542150), and NASA Arctic Boreal and Vulnerability Experiment (ABoVE) Legacy Carbon grant (grant \#Mack-01) to MCM. NJD was supported by an NSERC Postdoctoral Fellowship and Rutherford Postdoctoral Fellowship from the Royal Society of New Zealand. In kind support was provided by the Bonanza Creek LTER program. We thank the GNWT Aurora Research Inst. (Research License 15879), the Ka'a'gee Tu First Nation, the Tłıchǫ Government and the Wek'éezhì Renewable Resources Board for their support of this research. The Wilfrid Laurier University - GNWT Partnership Agreement was instrumental in providing logistical support and laboratory space.

Author contributions - NJD and ALW shared first authorship and contributed equally to this work. JLB, JFJ, MCM and MRT conceived the study with the help of NJD, SC and XJW. All coauthors designed the field sampling. ALW, NJD, XJW and GÉDT collected the field data and analysed the data with support from JLB and JFJ. ALW wrote the first draft of the manuscript with support from NJD, JLB and JFJ. NJD wrote subsequent drafts with support from ALW and JLB and all coauthors edited the manuscript.

\section{References}

Auguie, B. 2018. egg: extensions for 'ggplot2', to align plots and set panel sizes. $-<$ https://CRAN.R-project.org/package=egg $>$.

Baltzer, J. et al. 2020. Data from: Vascular plant community data for Northwest Territories, Canada. - Dryad Digital Repository, $<$ https://doi.org/10.5061/dryad.76hdr7sth>.

Bellingham, P. J. and Sparrow, A. D. 2000. Resprouting as a life history strategy in woody plant communities. - Oikos 89: 409-416.

Benjamini, Y. and Hochberg, Y. 1995. Controlling the false discovery rate: a practical and powerful approach to multiple testing. - J. R. Stat. Soc. B 57: 289-300.

Bernhardt, E. L. et al. 2011. Fire severity mediates climate-driven shifts in understorey community composition of black spruce stands of interior Alaska. - J. Veg. Sci. 22: 32-44.

Boby, L. A. et al. 2010. Quantifying fire severity, carbon and nitrogen emissions in Alaska's boreal forest. - Ecol. Appl. 20: $1633-1647$.

Boiffin, J. et al. 2015. Ecological controls on post-fire vegetation assembly at multiple spatial scales in eastern North American boreal forests. - J. Veg. Sci. 26: 360-372. 
Bond, W. J. and Midgley, J. J. 2001. Ecology of sprouting in woody plants: the persistence niche. - Trends Ecol. Evol. 16: 45-51.

Borcard, D. et al. 2011. Numerical ecology with R. - Springer.

Brandt, J. P. et al. 2013. An introduction to Canada's boreal zone: ecosystem processes, health, sustainability and environmental issues. - Environ. Rev. 21: 207-226.

Bridge, S. R. J. and Johnson, E. A. 2000. Geomorphic principles of terrain organization and vegetation gradients. - J. Veg. Sci. 11: 57-70.

Brose, U. and Hillebrand, H. 2016. Biodiversity and ecosystem functioning in dynamic landscapes. - Phil. Trans. R. Soc. B 371: 20150267.

Brouillet, L. et al. 2010. VASCAN, the database of vascular plants of Canada. - <http://data.canadensys.net/vascan/> accessed October 2017.

Canadian Interagency Forest Fire Centre 2014. Situation report - 22 Sep 2014. - <www.ciffc.ca/firewire/current.php?lang=en $\&$ date $=20140922>$.

Clarke, P. J. et al. 2013. Resprouting as a key functional trait: how buds, protection and resources drive persistence after fire. - New Phytol. 197: 19-35.

Coops, N. C. et al. 2018. A thirty year, fine-scale, characterization of area burned in Canadian forests shows evidence of regionally increasing trends in the last decade. - PLoS One 13: e0197218.

Day, N. J. et al. 2017. Annual dynamics and resilience in post-fire boreal understory vascular plant communities. - For. Ecol. Manage. 401: 264-272.

Day, N. J. et al. 2019. Wildfire severity reduces richness and alters composition of soil fungal communities in boreal forests of western Canada. - Global Change Biol. 25: 2310-2324.

De Grandpré, L. et al. 1993. Changes in the understory of Canadian southern boreal forest after fire. - J. Veg. Sci. 4: 803-810.

de Groot, W. J. et al. 2013. Climate change impacts on future boreal fire regimes. - For. Ecol. Manage. 294: 35-44.

Dray, S. and Dufour, A. 2007. The ade4 package: implementing the duality diagram for ecologists. - J. Stat. Softw. 22: 1-20.

Dray, S. and Legendre, P. 2008. Testing the species-traits-environment relationships: the fourth corner problem revisited. - Ecology 89: 3400-3412.

Dray, S. et al. 2014. Combining the fourth-corner and the RLQ methods for assessing trait responses to environmental variation. - Ecology 95: 14-21.

Ecosystem Classification Group 2008. Ecological regions of the Northwest Territories - Taiga Shield. - Dept of Environment and Natural Resources, Government of the Northwest Territories, Yellowknife, NT, Canada.

Ecosystem Classification Group 2009. Ecological regions of the Northwest Territories - Taiga Plains. - Dept of Environment and Natural Resources, Government of the Northwest Territories, Yellowknife, NT, Canada.

Enright, N. J. et al. 2011. Fire interval effects on persistence of resprouter species in Mediterranean-type shrublands. - Plant Ecol. 212: 2071-2083.

Environment and Climate Change Canada 2017. Station records for Yellowknife, Northwest Territories, Canada. $-<$ http://climate.weather.gc.ca/climate_normals/index_e.html>.

Gauthier, S. et al. 2015. Boreal forest health and global change. - Science 349: 819-822.

Grandin, U. and Rydin, H. 1998. Attributes of the seed bank after a century of primary succession on islands in Lake Hjälmaren, Sweden. - J. Ecol. 86: 293-303.
Greene, D. F. and Johnson, E. A. 1999. Modelling recruitment of Populus tremuloides, Pinus banksiana and Picea mariana following fire in the mixedwood boreal forest. - Can. J. For. Res. 29: 462-473.

Greene, D. F. et al. 2007. The reduction of organic-layer depth by wildfire in the North American boreal forest and its effect on tree recruitment by seed. - Can. J. For. Res. 37: 1012-1023.

Grime, J. P. 1977. Evidence for the existence of three primary strategies in plants and its relevance to ecological and evolutionary theory. - Am. Nat. 111: 1169-1194.

Hart, S. A. and Chen, H. Y. H. 2006. Understory vegetation dynamics of North American boreal forests. - Crit. Rev. Plant Sci. 25: 381-397.

Hollingsworth, T. N. et al. 2013. Fire severity filters regeneration traits to shape community assembly in Alaska's boreal forest. - PLoS One 8: e56033.

Johnson, D. et al. 1995. Plants of the Western Forest: Alaska to Minnesota Boreal and Aspen Parkland. - Lone Pine.

Johnstone, J. F. and Chapin, F. S. 2006. Effects of soil burn severity on post-fire tree recruitment in boreal forest. - Ecosystems 9: $14-31$.

Johnstone, J. F. et al. 2004. Decadal observations of tree regeneration following fire in boreal forests. - Can. J. For. Res. 34: 267-273.

Johnstone, J. F. et al. 2008. A key for predicting postfire successional trajectories in black spruce stands of interior Alaska. - United States Dept of Agriculture Forest Service Pacific Northwest Research Station General Technical Report PNW-GTR-767.

Johnstone, J. F. et al. 2010a. Fire, climate change and forest resilience in interior Alaska. - Can. J. For. Res. 40: 1302-1312.

Johnstone, J. F. et al. 2010b. Changes in fire regime break the legacy lock on successional trajectories in Alaskan boreal forest. - Global Change Biol. 16: 1281-1295.

Johnstone, J. F. et al. 2016. Changing disturbance regimes, ecological memory and forest resilience. - Front. Ecol. Environ. 14: 369-378.

Larsson, C. 2006. CooRecorder and Cdendro programs of the CooRecorder/Cdendro package, version 7.8. - <www.cybis.se/ forfun/dendro/> accessed March 2017.

Latifovic, R. et al. 2008. Land cover map of Canada 2005 at 250 m spatial resolution. - Natural Resources Canada/ESS/Canada Centre for Remote Sensing, <ftp://ftp.ccrs.nrcan.gc.ca/ad/ NLCCLandCover/LandcoverCanada2005_250m/> verified 6 October 2018.

Legendre, P. and Anderson, M. J. 1999. Distance-based redundancy analysis: testing multispecies responses in multifactorial ecological experiments. - Ecol. Monogr. 69: 1.

Lyon, L. and Stickney, P. 1974. Early vegetal succession following large northern Rocky Mountain wildfires. - Proceedings of the Tall Timbers fire ecology conference and intermountain fire land management symposium, pp. 355-373.

Noble, I. R. and Slatyer, R. O. 1980. The use of vital attributes to predict successional changes in plant communities subject to recurrent disturbances. - Vegetatio 43: 5-21.

Oksanen, J. et al. 2019. vegan: community ecology package. - R package ver. 2.4-2, <http://CRAN.R-project.org/ package $=$ vegan $>$.

Pausas, J. G. and Keeley, J. E. 2014. Evolutionary ecology of resprouting and seeding in fire-prone ecosystems. - New Phytol. 204: 55-65.

Pinno, B. and Errington, R. 2016. Burn severity dominates understory plant community response to fire in xeric jack pine forests. - Forests 7: 83. 
Porsild, A. and Cody, W. 1980. Vascular plants of continental Northwest Territories, Canada. - Canadian National Museum of Natural Sciences.

Purdon, M. et al. 2004. Initial response of understorey vegetation to fire severity and salvage-logging in the southern boreal forest of Québec. - Appl. Veg. Sci. 7: 49-60.

Romero-Lankao, P. et al. 2014. North America. - In: Barros, V. R. et al. (eds), Climate change 2014: impacts, adaptation and vulnerability. Part B: regional aspects. Contribution of working group II to the fifth assessment report of the intergovernmental panel on climate change. Cambridge Univ. Press, pp. 1439-1498.

Ryan, K. C. 2002. Dynamic interactions between forest structure and fire behavior in boreal ecosystems. - Silva Fenn. 36: 13-39.

Schimmel, J. and Granström, A. 1996. Fire severity and vegetation response in the boreal Swedish forest. - Ecology 77: 1436-1450.

Seidl, R. et al. 2016. Searching for resilience: addressing the impacts of changing disturbance regimes on forest ecosystem services. - J. Appl. Ecol. 53: 120-129.

Simpson, K. J. et al. 2019. Frequent fires prime plant developmental responses to burning. - Proc. R. Soc. B 286: 20191315.

Stralberg, D. et al. 2020. Climate-change refugia in boreal North America: what, where and for how long? - Front. Ecol. Environ. 18: 261-270.

Turner, M. G. et al. 1997. Effects of fire size and pattern on early succession in Yellowstone National Park. - Ecol. Monogr. 67: 411-433.

Supplementary material (available online as Appendix ecog05211 at <www.ecography.org/appendix/ecog-05211>). Appendix 1.
USDA 2017. Fire effects information system. - <www.fs.usda.gov/ $\mathrm{rmrs} /$ tools/fire-effects-information-system-feis $>$.

van Cleve, K. et al. 1991. Element cycling in Taiga forests: statefactor control. - BioScience 41: 78-88.

Walker, X. J. et al. 2018a. Cross-scale controls on carbon emissions from boreal forest megafires. - Global Change Biol. 24: 4251-4265.

Walker, X. J. et al. 2018b. Soil organic layer combustion in boreal black spruce and jack pine stands of the Northwest Territories, Canada. - Int. J. Wildland Fire 27: 125-134.

Walker, X. J. et al. 2018c. ABoVE: wildfire carbon emissions at 30-m resolution, Northwest Territories, CA, 2014. - ORNL DAAC.

Walker, X. J. et al. 2019. Increasing wildfires threaten historic carbon sink of boreal forest soils. - Nature 572: 520-523.

Whitman, E. et al. 2018. Topoedaphic and forest controls on postfire vegetation assemblies are modified by fire history and burn severity in the northwestern Canadian boreal forest. - Forests 9: 151 .

Wickham, H. 2017. tidyverse: easily install and load the 'Tidyverse'. - $\mathrm{R}$ package ver. 1.2.1.

Wotton, B. M. et al. 2017. Potential climate change impacts on fire intensity and key wildfire suppression thresholds in Canada. - Environ. Res. Lett. 12: 095003.

Zhang, T. et al. 1999. Statistics and characteristics of permafrost and ground-ice distribution in the Northern Hemisphere. - Polar Geogr. 23: 132-154. 